\title{
Conferências Nacionais de Educação: intelectuais, Estado e discurso educacional (1927-1967)*
}

\section{National Conferences of Education: intellectuals, state and educational discourse (1927-1967)}

\author{
Carlos Eduardo Vieira**
}

\begin{abstract}
RESUMO
O presente artigo tem como objeto o discurso educacional enunciado ao longo das treze Conferências Nacionais de Educação (CNEs), organizadas pela Associação Brasileira de Educação (ABE) e realizadas entre 1927 e 1967. Em termos metodológicos, assumimos os pressupostos do contextualismo linguístico, em especial, a noção de linguagem complexa. Privilegiaremos a caracterização da $\mathrm{ABE}$ e dos seus eventos, as relações da ABE com o Estado, assim como formularemos uma hipótese sobre a estruturação do discurso educacional. O corpus documental da pesquisa é composto de documentos de natureza diversificada, tais como atas, correspondências, notícias veiculadas em jornais, conferências e moções apresentadas durante as CNEs. No estudo realizado, pudemos identificar a ABE e as CNEs como lugares privilegiados para projetar uma intelligentsia autorizada a falar sobre os problemas e, sobretudo, sobre as metas e as prioridades da educação nacional. O estudo das CNEs revelou, também, que os congressos educacionais cumpriram múltiplas funções, entre as quais destacamos: dar visibilidade às ações do Estado; legitimar os intelectuais envolvidos com a direção das reformas educacionais; conquistar o consentimento da sociedade em geral e da comunidade escolar em particular para a implementação das mudanças pretendidas; e, por fim, estruturar o discurso educacional, que pretendia a organização nacional a partir da reforma da cultura e da escola.
\end{abstract}

Palavras-chave: Associação Brasileira de Educação. Conferências Nacionais de Educação. Intelectuais. Reformas educacionais. Discurso educacional.

DOI: $10.1590 / 0104-4060.53670$

* A pesquisa, na qual este artigo está vinculado, é financiada pelo Conselho Nacional de Pesquisa (CNPq), na modalidade Bolsa Produtividade, processo n. 305908/2016-2.

** Universidade Federal do Paraná. Setor de Educação. Curitiba, Paraná, Brasil. Rua General Carneiro, nº 460. Centro. CEP: 80060-150. E-mail: cevieira9@gmail.com. 


\begin{abstract}
The article has as its object the educational discourse enunciated throughout the thirteen National Conferences of Education (CNEs), organized by the Brazilian Association of Education (ABE) and carried out between 1927 and 1967. In methodological terms, we have the conjectures of linguistic contextualism as a basis, in particular the notion of complex language. We will privilege the characterization of the $\mathrm{ABE}$ and its events, and the relations between the $\mathrm{ABE}$ and the State; we will also formulate a hypothesis about the structuring of educational discourse. The sources of the research are documents of a diverse nature, such as correspondences, newspapers, conferences and motions presented during the CNEs. In the study, we were able to identify the $\mathrm{ABE}$ and the CNEs as privileged places to project an intelligentsia with the authority to talk about the problems and, above all, about the goals and priorities of the national education. The study of the CNEs also revealed that the educational congresses fulfilled multiple functions, among which we highlight: giving visibility to the actions of the State; legitimizing the intellectuals involved in the direction of educational reforms; winning the consent of society in general and of the school community in particular for the implementation of intended changes; and, finally, structuring educational discourse.
\end{abstract}

Keywords: Brazilian Association of Education. National Education Conferences. Intellectuals. Educational reforms. Educational discourse.

\title{
Introdução
}

O presente artigo tem como objeto o discurso educacional enunciado ao longo das treze Conferências Nacionais de Educação (CNEs), organizadas pela Associação Brasileira de Educação (ABE) e realizadas entre 1927 e 1967. Em termos científicos amplos, a problematização desse objeto gravita em torno de três articuladores: a prática social dos intelectuais vinculados à $\mathrm{ABE}$ e às CNEs; as relações da $\mathrm{ABE}$ com o Estado e as reformas educacionais; e as características do discurso educacional enunciado nestes espaços de debate público ${ }^{1}$.

Em termos metodológicos, assumimos na análise os pressupostos do contextualismo linguístico. Esta teoria da interpretação foi desenvolvida, es-

1 Não problematizaremos neste artigo a categoria intelectuais, já que realizamos este tipo de análise em trabalhos já publicados. Para uma visão da forma como compreendemos os intelectuais vinculados ao campo educacional brasileiro, veja Erasmo Pilotto: identidade, engajamento político e crenças dos intelectuais vinculados ao campo educacional no Brasil. (VIEIRA, 2011). 
pecialmente, pelos historiadores do pensamento político John Pocock (2003) e Quentin Skinner $(1999,2002)$. Pocock, em particular, sustenta a ideia do discurso político como uma linguagem complexa, na qual coabitam léxicos oriundos de diversas procedências sociais, religiosas, disciplinares e profissionais. O encontro desses léxicos ocorre no âmbito de um contexto de uso da linguagem, no qual os termos provenientes de diferentes linguagens assumem sentidos próprios do discurso político. A noção do discurso político como linguagem complexa guia nossas hipóteses de interpretação sobre o discurso educacional, uma vez que percebemos nas enunciações, presentes nas fontes das CNEs, uma convergência de linguagens e formas lexicais que, associadas, produziram o modo particular de falar sobre a educação no período.

Em breves e esquemáticas palavras, a perspectiva do contextualismo possibilita entendermos o discurso educacional como um jogo de linguagem, a partir da compreensão do comportamento linguístico dos seus atores ${ }^{2}$. Essa abordagem propicia, assim, estudar a variedade linguística praticada por aqueles que pretenderam difundir e criar modos de argumentação e, por extensão, meios de persuasão associados aos projetos dos atores envolvidos na sua enunciação. Pocock (2003) sistematiza os procedimentos de interpretação da estrutura e do funcionamento das linguagens em duas etapas: inicialmente, ele indica a necessidade de identificação dos termos básicos (léxico ou linguagem normativa) presentes no discurso que se pretende analisar para, então, flagrar as ocasiões nas quais os termos aparecem e os modos como se complementam ou se opõem.

Essa operação demanda uma leitura exaustiva dos textos e um exercício de formulação de hipóteses sobre as características do discurso analisado. Nos termos propostos por Pocock, o funcionamento normal do discurso, bem como os momentos de subversão da sua estrutura normativa - chamados por ele de lances (throw) - podem ser percebidos no interior de uma linguagem delimitada temporalmente. O uso de estratégias de interpretação do contextualismo possibilita demonstrar historicamente como um conjunto de falantes partilharam um determinado meio expressivo. Para Pocock (2003, p. 74), é "do métier do historiador aprender uma série de linguagens e estabelecê-las como contextos em que são efetuados os atos de enunciação". O jogo de linguagem, como supõe a metáfora, é um lugar de disputas, sendo assim, ao compreendermos o seu funcionamento, somos capazes de identificar e qualificar os atores envolvidos e entender os conflitos materiais e simbólicos que marcam a experiência desses personagens.

2 Na perspectiva de Wittgenstein, apropriada pelo contextualismo, jogos de linguagem são situações estruturadas de enunciação que impõem regras, tacitamente aceitas pelos jogadores, sobre o que é possível ser dito, por quem, quando e como. 
Apresentados esses pressupostos teóricos, podemos formular com maior precisão o objetivo que orienta a pesquisa na qual este artigo se insere e representa parte inicial dos seus resultados: compreender discurso educacional, enunciado pela ABE e pelas CNEs no período de 1927 a 1967, considerando a sua composição histórico-lexical, o seu funcionamento como jogo de linguagem compartilhado e os seus diversificados usos políticos, sociais, científicos e/ou educacionais. Assim, no espaço desse artigo, trataremos da caracterização da $\mathrm{ABE}$ e dos seus eventos (CNEs), suas relações com o Estado, bem como, no âmbito das conclusões, formularemos uma primeira hipótese da estruturação do discurso educacional, entendido a partir do conceito de linguagem complexa.

$\mathrm{Na}$ investigação localizamos e examinamos globalmente as fontes das treze CNEs. Nesse sentido, organizamos e catalogamos o corpus documental da pesquisa, o qual encontra-se, principalmente, no acervo da $\mathrm{ABE}$, localizado na cidade do Rio de Janeiro. Entre os documentos mobilizados, destacamos os seguintes tipos: atas do Conselho Diretor da $\mathrm{ABE}$; correspondência da ABE; atas de sessões de abertura das CNEs; atas de sessões das CNEs; documentos conclusivos das CNEs; conferências de abertura das CNEs; moções apresentadas durante as CNEs; pareceres, programas e relatórios das CNEs; relação de participantes das CNEs; teses apresentadas durante as CNEs; e notícias veiculadas em jornais e revistas ${ }^{3}$.

\section{Associação Brasileira de Educação e as suas conferências nacionais}

Muitos trabalhos investigaram e problematizaram as CNEs e a ABE; contudo, predominam os estudos de aspectos particulares e de recortes temporais restritos a uma ou a um grupo de conferências. A I CNE, realizada em Curitiba em 1927, é a mais estudada das conferências, tendo como exemplos os seguintes trabalhos: Ferreira (1988), Schmidt (1997), Galter (2002), Bona Jr. (2005), Vieira (2007) e Vieira e Bona Jr. (2007). Entre os estudos que investem em um conjunto de conferências, podemos destacar Carvalho (1998), que aborda os primeiros oito anos da $\mathrm{ABE}$ a partir da análise das noções de higiene, moral e trabalho; Linhales (2006), que reflete sobre o esporte e a Educação Física na ABE, entre 1925 e 1935; Strang (2008), que discute o comportamento dos in-

3 A documentação encontrada e identificada, que testemunha as treze CNEs, não se encontra no mesmo grau de conservação e de completude, de maneira que verificamos lacunas na composição do corpus documental da pesquisa. 
telectuais, entre a criação da $\mathrm{ABE}$ e a ruptura destes com a associação nos anos de 1930; Marques (2008), que analisa o discurso patriótico da ABE durante a Segunda Guerra Mundial; e Valério (2013), que problematiza a questão do ensino secundário a partir da relação entre Estado e sociedade civil. Percebe-se que não existem estudos que analisam o conjunto das CNEs; contudo, gostaríamos de destacar que - particularmente em Carvalho (1998), Bona Jr. (2005), Strang (2008), Vieira (2007), Vieira e Bona Jr. (2007) e Valério (2013) - vislumbramos as preocupações de análise do contexto da $\mathrm{ABE}$ e dos CNEs, a partir de ferramentas metodológicas próprias da análise do discurso.

Consideramos as CNEs momentos privilegiados para flagrarmos o discurso educacional, pois essas conferências foram eventos nacionais que reuniram os principais protagonistas do debate educacional, sejam eles personagens consagrados, sejam indivíduos sem notoriedade no campo ${ }^{4}$. Não obstante, embora em posições diferentes, eles interagiram no processo de produção de um jogo de linguagem particular. Jogo que continha regras de enunciação compartilhadas, modos específicos de argumentação e usos variados do léxico disponível, de acordo com os horizontes ideológicos dos atores envolvidos e da natureza dos projetos em disputa. A longevidade e a frequência do evento, bem como a diversidade e as diferentes posições ocupadas pelos intelectuais engajados nas CNEs, propiciam a decifração das continuidades e das descontinuidades presentes no interior do discurso educacional entre as décadas de 1920 e 1960.

As Conferências Nacionais de Educação (CNEs), no período que foi estabelecido para pesquisa, foram as seguintes (Tabela 1):

4 O conceito de campo de Pierre Bourdieu (1998) não se constitui em um aparato heurístico central nessa análise; contudo, quando utilizamos a expressão, estamos apoiados na ideia bourdiana que define o campo como espaço social de relações, em que são estabelecidos/impostos os critérios de nomeação, de classificação e de distinção social. Bourdieu ressalta a relação entre os campos, mas sustenta, também, a autonomia relativa desses espaços. 
TABELA 1 - CNES - 1927-1967

\begin{tabular}{|l|l|l|}
\hline Ano & Local & Tema(s) \\
\hline 1927 & Curitiba & Organização nacional do ensino primário. \\
\hline 1928 & Belo Horizonte & Ensino secundário. \\
\hline 1929 & São Paulo & Ensinos secundário, primário e profissional; educação sanitária. \\
\hline 1931 & Rio de Janeiro & Diretrizes para a educação popular. \\
\hline 1933 & Niterói & Elaboração do anteprojeto de organização nacional da educação. \\
\hline 1934 & Fortaleza & Organização geral do ensino no país. \\
\hline 1935 & Rio de Janeiro & Educação física. \\
\hline 1942 & Goiânia & A educação primária: objetivos e organização. \\
\hline 1945 & Rio de Janeiro & Conceito de educação democrática. \\
\hline 1950 & Rio de Janeiro & $\begin{array}{l}\text { Conferência convocada com o objetivo de obter sugestões para a } \\
\text { Lei de Diretrizes e Bases (LDB). }\end{array}$ \\
\hline 1954 & Curitiba & Financiamento dos sistemas públicos de educação. \\
\hline 1956 & Salvador & $\begin{array}{l}\text { Contribuição da escola à compreensão e à utilização das } \\
\text { descobertas científicas. Os processos da educação democrática } \\
\text { nos diversos graus de ensino e na vida extraescolar. }\end{array}$ \\
\hline 1967 & Rio de Janeiro & Educação para o desenvolvimento da Ciência e da Tecnologia. \\
\hline
\end{tabular}

FONTE: Elaborado por Telma Faltz Valério.

A ABE foi criada em 1924 e, conforme a ata da sua reunião de fundação,

realizada depois de algumas outras preparatórias, foram aprovados os Estatutos da Associação e eleitos, em seguida, para o Conselho Diretor, os 6 membros a que se refere o parágrafo $1^{\circ}$ do artigo $4^{\circ}$ dos referidos Estatutos. Os eleitos foram: Heitor Lyra da Silva, Levi Fernandes Carneiro, Antonio Carneiro Leão, D. Bertha Lutz, Mario Paulo de Brito e Vicente Licínio Cardoso, sendo que o penúltimo para secretário geral e o último para tesoureiro. (ABE, Atas, 1924, p. 1).

A fundação da $\mathrm{ABE}$ foi o resultado da reunião de professores, normalistas, jornalistas, médicos, advogados e engenheiros em torno de um objetivo manifesto: sensibilizar a nação para a questão educacional que, segundo a leitura desses intelectuais, mesmo após o advento da república, permanecia à margem das iniciativas do Estado. Nesse sentido, em seu estatuto, no art. $1^{\circ}$, a entidade afirma: "a Associação Brasileira de Educação tem por fim promover no Brasil a difusão e o aperfeiçoamento da educação em todos os seus ramos, estimulando as iniciativas que possam mais eficazmente atingir estes objetivos" (ABE, Estatuto, 1924, p. 7). No detalhamento dos objetivos da entidade identificamos: 
$1^{\circ}$ Organizar permanentemente a estatística da instrução no Brasil; $2^{\circ}$ Publicar revista, boletins e relatórios periódicos, sobre questões de educação e instrução; $3^{\circ}$ Manter museu escolar permanente, biblioteca pedagógica, sala de conferências e cursos; $4^{\circ}$ Promover e premiar a elaboração e a publicação de bons livros didáticos; $5^{\circ}$ Promover congressos de educação regionais ou nacionais; $6^{\circ}$ Promover a representação do Brasil, em congressos de educação no estrangeiro; $7^{\circ}$ Organizar um arquivo de legislação nacional e estrangeira, sobre ensino e questões correlatas; $8^{\circ}$ Facilitar a seus sócios a aquisição de livros e de material escolar; $9^{\circ} \mathrm{Co}-$ operar em todas as obras de educação física, moral e cívica; $10^{\circ}$ Facilitar o desenvolvimento do cinema educativo, de bibliotecas infantis, e de outros institutos auxiliares de ensino; $11^{\circ}$ Auxiliar a intercorrespondência escolar, nacional e estrangeira; $12^{\circ}$ Organizar obras de mutualidade entre professores e entre alunos; $13^{\circ}$ Estudar e auxiliar a educação popular quer quanto à cultura intelectual, moral e física, quer quanto à instrução profissional (ABE, Estatuto, 1924, p. 7).

Os intelectuais reunidos na $\mathrm{ABE}$ reafirmaram o bordão, presente no cenário intelectual brasileiro desde o século XIX, da missão das elites cultas na formação da consciência nacional. Essa consciência cívica teria na escola primária o seu lugar privilegiado de formação, disseminando condutas e sentimentos associados às ideias de laboriosidade, ordem, higiene e civismo. Nos três primeiros anos de existência da $\mathrm{ABE}$, seus debates e ações ficaram restritas a pequenos círculos e à capital federal, limitando-se, principalmente, aos intelectuais que a compunham. Porém, a partir de 1927, esta entidade procurou dar maior visibilidade e abrangência as suas teses quando passou a promover conferências em âmbito nacional. As CNEs seriam, de acordo com o regimento definido pela $\mathrm{ABE}$, promovidas anualmente. A ata da reunião preparatória da I $\mathrm{CNE}$ revela esse objetivo:

Prosseguindo na execução de seu programa educacional, resolve a Associação Brasileira de Educação realizar, em todos os Estados do Brasil, conferências nacionais de educação com a participação de todas as unidades federativas, visando à congregação de todos os professores brasileiros em torno dos mais elevados ideais de civismo e de moral. Combate-se destarte o espírito separatista que por vezes se revela aqui, ou ali, trabalhando-se nobremente pela unidade nacional (ABE, Atas, 1927, não p.). 
No total foram realizadas treze CNEs entre os anos de 1927 a 1967, sendo a primeira realizada em Curitiba e a última no Rio de Janeiro. Nesse sentido, a I CNE representou o início de uma sequência de encontros nacionais que delinearam um projeto de intervenção social e cultural de grande magnitude. A crença na relação entre educação e modernidade mobilizou a intelectualidade abeana, e Mário Pinto Serva, participante da I CNE, expressou de forma lapidar esse sentido que acompanhou o discurso da associação e das conferências nacionais ao longo do período desse estudo:

o problema da educação do povo brasileiro é o mais nacional de todos os problemas. É o maior problema da história nacional. É quase o único problema nacional, porque a educação, generalizada e ampla, naturalmente por si, resolve todos os demais problemas. É a infraestrutura da organização coletiva (I CNE, Tese 103, 1927, não p.).

As CNEs adotaram uma sistemática de organização que pouco se alterou ao longo das treze conferências, cabendo destaque para os temas principais de cada evento, as sessões temáticas e a presença de teses da diretoria, que funcionavam como guias para os debates. Entre os temas das CNEs, destacamos: organização nacional do ensino primário, na I CNE; o ensino secundário, na II CNE; subsídios para a elaboração do anteprojeto do Plano Nacional da Educação, V CNE; a educação física, na VII CNE; o conceito de educação democrática, na IX CNE; subsídios para a lei de diretrizes e bases (LDB), na X CNE; financiamento da educação, na XI CNE; e educação para o desenvolvimento da Ciência e da Tecnologia, na XIII CNE. As conferências obedeceram ao critério da anualidade apenas entre 1927 e 1929 e entre 1933 e 1935 . Dois grandes hiatos são notados na periodicidade do evento entre 1936 e 1941 e entre 1957 e 1966. Apesar dos hiatos na realização, a longevidade da associação e a frequência dos eventos foram significativas nesse período, uma vez que as regras eram a efemeridade e a descontinuidade dos eventos, associações e publicações do campo educacional ${ }^{5}$.

5 A Associação Brasileira de Educação (ABE) permanece funcionando até o presente momento e tem sede na cidade do Rio de Janeiro. 


\section{ABE e CNEs: a centralidade do Estado como agente de transformação social}

É claramente perceptível, na documentação da entidade e dos eventos, a preocupação da associação em eleger o Estado como seu principal interlocutor. $\mathrm{Na}$ pesquisa que realizamos das fontes, verificamos, por um lado, a presença no interior do discurso abeano da crença no papel do Estado como o agente político e administrativo capaz de produzir, em nível nacional, a reforma intelectual e moral da população brasileira pretendida pela associação. Por outro, também observamos a permanente ação do Estado no sentido de manter a ABE tutelada nos marcos dos seus projetos políticos. Os temas discutidos na $\mathrm{ABE}$ e nas CNEs refletem demandas do Estado, assim como identificamos que os abeanos compreendiam os resultados das CNEs como subsídios para as políticas públicas de educação. Lourenço Filho, destacado quadro da ABE, afirmou que:

as conferências nacionais de educação não devem nem podem ser congressos de natureza técnica ou científica. O que devem é constituírem-se como centros de estudo de uma política nacional em matéria educativa. Uma intenção social profunda deve animá-las, mesmo porque só essa intenção as explica e as recomenda ao apoio e confiança dos governos (ABE, Notícias da II CNE, 1929, p. 21).

O interlocutor privilegiado foi também o objeto de disputa, na perspectiva de ocupação de cargos estratégicos no aparelho estatal e/ou pela influência na formulação das políticas públicas. Nesse período, a demanda pela ampliação do acesso à escolarização na sociedade brasileira, advinda dos mais variados estratos sociais, levou o Estado e os grupos políticos, que disputavam o poder na sociedade brasileira, a cooptarem quadros importantes da intelectualidade para gerirem projetos, instituições e reformas nas políticas públicas para a educação. A luta pela ocupação desses espaços institucionais em Estados e cidades importantes da federação levou à cristalização de tendências intelectuais que organizaram a $\mathrm{ABE}$ e as conferências nacionais nos moldes de um púlpito voltado para o Estado e para os grupos políticos e econômicos atuantes.

A tensão gerada por essas disputas, em torno da direção do projeto educacional para o país, levou ao conflito mais profundo da história da entidade, entre o laicato católico e os seus adversários defensores da laicidade da escola pública. Isso aconteceu nas vésperas da Constituinte de 1934, no cenário da V 
CNE. Nesse episódio, verificamos os católicos militantes criticando a diretoria da $\mathrm{ABE}$ pela adesão ao Estado e às teses anticatólicas e comunistas. Essa crítica levou a diretoria da ABE a manifestar-se em carta aberta, publicada no jornal carioca $A$ Pátria:

Provavelmente há esta hora já lestes ou ouvistes murmurar três acusações contra a Associação Brasileira de Educação. Que ela é uma 'chancella de homens de governo, um foco de anticatholicismo e um foco de communismo '. [...] Lêde a nossa exposição, vinde a nossa sede apurar testemunhos, consultar as atas das sessões, ou nomeae, se quezerdes, uma comissão para verificar os fatos. Ficareis conhecendo os tristes motivos pessoais que são a origem real dessas acusações. Fecareis sabendo que elas são revoltantemente falsas. A associação não violou uma só vez a neutralidade política e religiosa sobre cujas bases seguras a edificou o homem digno, culto, honesto e veraz que foi Heitor Lyra da Silva (ABE, Carta Aberta aos Sócios, não p., 20/01/1933).

Esse episódio é ilustrativo do clima de disputa que se estabeleceu em alguns momentos da experiência da associação e, sobretudo, da questão da relação entre a $\mathrm{ABE}$ e o Estado. No horizonte, desses conflitos, estava o objetivo de dirigir e de organizar o projeto de inserção do Brasil na modernidade por meio das reformas educacionais.

$\mathrm{A} A B E$ e as suas conferências tiveram como foco a intervenção política, de maneira que, ao analisar a criação da $\mathrm{ABE}$, Carvalho destacou que "foi do malogro da organização do partido político Acção Nacional que nasceu a Associação Brasileira de Educação" (CARVALHO, 1998, p. 54). Essa interpretação tem sustentação nas palavras de Lourenço Filho, então presidente da $\mathrm{ABE}$, no contexto da VII CNE:

Há pouco mais de dez anos, preocupados com o rumo dos acontecimentos sociais e políticos do país, reuniram-se alguns homens de boa vontade, tendo a frente essa singular figura, que foi Heitor Lyra da Silva; e entre a ideia da organização de um novo partido político, e a de fundar-se uma agremiação em prol da cultura nacional resolveram optar por esta última. [...], esse programa era e é político, no melhor e mais elevado do termo. Político, no sentido de avivar em todos os espíritos, responsáveis pelas coisas do Brasil, a fé nas coisas de educação; e político, no sentido de esclarecer a opinião pública no tocante aos problemas de organização 
nacional, por meio de uma organização de cultura. (ANAIS, VII CNE, 1935 , p. 21-22).

Da parte do Estado não faltaram acenos para $\mathrm{ABE}$ intervir na cena política, como se pode verificar na ocasião da IV CNE, quando Getúlio Vargas e Francisco Campos, Ministro da Educação, em seus discursos na abertura do evento, pediram aos conferencistas que fornecessem ao governo provisório a "“fórmula feliz', o 'conceito de educação' da nova política educacional” (CARVALHO, 1998, p. 380). A ocupação de cargos pelos intelectuais abeanos na gestão do Estado, tanto em nível federal quanto estadual, foi uma constante ao longo do período, de maneira que acompanhamos a argumentação de Valério que sustenta que

as Conferências Nacionais de Educação constituíram-se em espaço estruturado pelos intelectuais abeanos com o objetivo de, contando com uma extensão da $\mathrm{ABE}$ em cada estado, disseminar as políticas estruturadas pela $\mathrm{ABE}$ e ocupar o espaço governamental. Tal ocupação viabilizaria a efetivação de uma política nacional de educação e um amplo programa de ação social no país. Para tanto, precisavam do Estado financiando e apoiando as decisões ali tomadas, em uma relação conveniente para o governo, que, por seu turno, buscava o apoio dos diversos setores da sociedade civil para implementar sua política (VALÉRIO, 2013, p. 82).

$\mathrm{A} A B E$ e as CNEs surgiram em um momento de intensificação das mudanças nas políticas públicas para educação, nos principais estados da federação e no Distrito Federal, na década de 1920. O movimento de reformas segue ao longo do período, culminando no longo debate em torno da aprovação da primeira Lei de Diretrizes e Bases da Educação Nacional, na década de 1960. Dessa forma, constatamos que a ABE manteve-se atuante, ao longo de todo o período delimitado nessa pesquisa, na discussão sobre as políticas públicas para educação. As reformas atingiram diretamente a organização jurídica do ensino e da escola, reverberando sobre as práticas de planejamento e de controle dos processos educacionais, bem como sobre a formação e a profissionalização do magistério. 


\section{À guisa de conclusões: estruturação do discurso educacional}

Em termos propriamente discursivos, pudemos verificar a hipótese que orienta esse estudo sobre a produção no discurso educacional, entendido como uma linguagem complexa. Verificamos que a estruturação desse discurso ocorreu a partir da combinação de termos próprios de outros jogos de linguagem, particularmente daqueles praticados nos contextos dos discursos médico, religioso, político, científico (biológico, psicológico e sociológico) e econômico. Não obstante, esses termos, ao serem absorvidos no interior do discurso educacional, ganharam novos significados e usos próprios do jogo de linguagem compartilhado no processo de formação do campo educacional no Brasil. A presença desses termos varia ao longo do período estudado, de maneira que expressões originárias do léxico religioso (vocação, missão ou sacerdócio) e médico (higiene ou saneamento), com forte presença nos anos de 1920 a 1930, paulatinamente cedem espaço para palavras oriundas do discurso científico (aprendizagem, natureza, sociedade ou indivíduo) e econômico (desenvolvimento ou profissionalização), que passam a pontificar na formação do discurso educacional nos anos de 1950 a 1960. Entretanto, os termos oriundos da linguagem política (cidadania, república ou ordem) perpassam e se mantêm frequentes ao longo de todo o período estudado (Figura 1).

\section{FIGURA 1 - ESQUEMA EXPLICATIVO DO FUNCIONAMENTO DO DISCURSO EDUCACIONAL VEICULADO NAS TREZE CNES.}

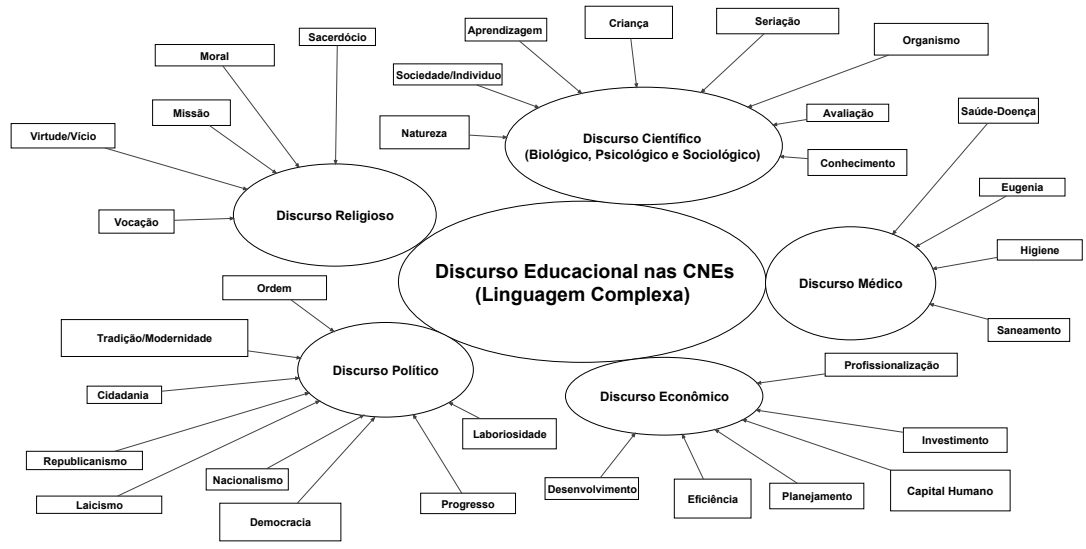

FONTE: Elaborada pelo Autor, a partir do software Visual Understanding Environment (VUE). 
A identificação da composição lexical desse discurso não se resume à frequência de uso das palavras, embora esta seja um ponto de partida e um índice importante. Contudo, para além da frequência, buscamos identificar o impacto semântico de determinados termos na estruturação dos sentidos em disputa no campo educacional. Disputas discursivas e simbólicas que evidenciam ações políticas e possíveis mudanças no plano das práticas educacionais. Assim, ainda que não possamos estabelecer uma relação causal entre discurso e prática, entre palavras e ações, podemos adotar como hipótese que mudanças na linguagem são indícios de mudanças nas práticas. Como afirmou Skinner (1999, p. 86): “o que é possível fazer em política é geralmente limitado pelo que é possível legitimar. O que se pode esperar legitimar, contudo, depende de que curso de ação se pode plausivelmente alcançar sob princípios normativos existentes". Em direção similar, Pocock afirma que "o historiador é, sem dúvida, perfeitamente consciente de que as coisas acontecem aos seres humanos antes de serem verbalizadas, embora não antes de eles possuírem os meios de verbalizá-las" (2003, p. 56).

Nesta chave de leitura, segundo Vieira (2017), estudar as práticas educacionais pressupõe entender o jogo de linguagem praticado, considerando o léxico corrente em cada contexto, bem como os termos que, no interior desse jogo, assumem contornos de conceitos normativos. Em outras palavras, as variações nos modos de falar sobre a educação - entre os anos de 1920 a 1960, oscilando entre os termos oriundos dos discursos religioso, médico, científico, político e econômico - são indícios de mudanças na percepção da educação e, sobretudo, das suas políticas e práticas. É possível supor que as mudanças na linguagem, a um só tempo, refletem e promovem alterações no plano das práticas ${ }^{6}$. Assim a alteração percebida no jogo de linguagem analisado, entre o léxico religioso dos anos de 1920 a 1930 e o léxico científico e econômico dos anos de 1950 a 1960, indica mudanças nas formas de pensar, sentir e agir em relação à educação. Entretanto, a presença constante da linguagem política (nação, cidadania ou democracia) evidencia permanências e continuidades na percepção da educação como parte da política, das ações que pretendem intervir sobre o mundo social.

Importante mencionar que, no plano da análise discursiva, os termos e os sentidos que coabitam um mesmo jogo de linguagem não são superados ou cancelados quando uma nova forma de conversação se estabelece. Termos como

6 A apropriação, realizada pelo contextualismo da teoria dos atos de fala desenvolvida por John Austin, prevê a percepção do funcionamento da linguagem a partir de três princípios: locução (capacidade de refletir o mundo), ilocução ou força ilocucionária (intenção do falante) e perlocução (efeito da fala sobre a plateia). Esta última categorização sugere a noção de que as palavras são atos, performances, que provocam mudanças no mundo social. 
missão ou sacerdócio, do léxico religioso, que foram amplamente mobilizados para definir o professor e o seu papel, seguem presentes no discurso educacional, carregando camadas de significados que permanecem produzindo sentidos. Não obstante, se esses termos não desapareceram, suas posições na conversação pública e, por extensão, na disputa pela produção de sentidos se alteraram significativamente. Logo, argumentar sobre o projeto de educação nacional nos anos de 1950, mobilizando um léxico científico ou econômico, implicava em ocupar uma posição de maior força nos debates em espaços públicos, como a imprensa ou o Estado.

Por fim, no estudo realizado, pudemos identificar as CNEs como lugares privilegiados para projetar a autoridade de uma intelligentsia autorizada a falar sobre os problemas e, sobretudo, sobre as metas e as prioridades da educação nacional. A pesquisa revela que os congressos educacionais cumpriram múltiplas funções, entre as quais destacamos: dar visibilidade às ações do Estado; legitimar os intelectuais envolvidos com a direção das reformas; conquistar o consentimento da sociedade, em geral, e da comunidade escolar, em particular, para a implementação das mudanças pretendidas; e, finalmente, estruturar o discurso educacional que, a partir da combinação de termos e sentidos, pretendia afirmar valores e sensibilidades, definir hierarquias e prioridades e, sobretudo, mobilizar práticas sociais.

\section{REFERÊNCIAS}

BONA JR., A. Educação e modernidade nas conferências educacionais da década de 1920 no Paraná. Dissertação (Mestrado em Educação) - Universidade Federal do Paraná, Curitiba. 2005.

BOURDIEU, P. O poder simbólico. Rio de Janeiro: Bertrand do Brasil, 1998.

CARVALHO, M. M. C. de. Molde Nacional e Fôrma Cívica: higiene, moral e trabalho no projeto da Associação Brasileira de Educação (1924-1931). Bragança Paulista: EDUSF, 1998.

FERREIRA, S. C. A I Conferência Nacional da Educação (contribuição para o estudo das origens da Escola Nova no Brasil). Dissertação (Mestrado em Educação) - Universidade Federal de São Carlos, São Carlos. 1988.

GALTER, M. I. Educação pública e modernização social no Brasil na Conferência de Educação de 1927. Dissertação (Mestrado em Educação) - Universidade Estadual de Maringá, Maringá. 2002. 
LINHALES, M. A. A escola, o esporte e a "energização do caráter": projetos culturais em circulação na Associação Brasileira de Educação (1925-1935). Tese (Doutorado em Educação) - Universidade Federal de Minas Gerais, Belo Horizonte. 2006.

MARQUES, G. D. Cartas em tempos de guerra: uma missão patriótica da Associação Brasileira de Educação (1942-1945). Dissertação (Mestrado em Educação) - Universidade Federal do Rio de Janeiro, Rio de Janeiro. 2008.

POCOCK, J, G, A. Linguagens do ideário político. São Paulo: EDUSP, 2003.

SCHMIDT, M. A. M. dos S. Infância: sol do mundo. A primeira conferência nacional de educação e a construção da infância brasileira. Tese (Doutorado em História) - Universidade Federal do Paraná, Curitiba. 1997.

SKINNER, Q. Visions of politics: regarding method. V. 1. Cambridge: Cambridge University Press, 2002.

SKINNER, Q. Liberdade antes do liberalismo. São Paulo: UNESP, 1999.

STRANG, B. de L. S. O saber e o credo: os intelectuais católicos e a doutrina da Escola Nova (1924-1940). Tese (Doutorado em Educação) - Pontifícia Universidade Católica do Rio de Janeiro, Rio de Janeiro. 2008.

VALÉRIO, T. F. Associação Brasileira de Educação: as Conferências Nacionais de Educação como estratégias de intervenção da intelectualidade abeana na política educacional do ensino secundário no Brasil (1928-1942). Tese (Doutorado em Educação) - Universidade Federal do Paraná, Curitiba. 2013.

VIEIRA, C. E. Intelectuais e o Discurso da Modernidade na I Conferência Nacional de Educação (Curitiba - 1927). In: BENCOSTTA, M. L. Culturas Escolares, Saberes e práticas educativas: itinerários históricos. São Paulo: Cortes, 2007.

VIEIRA, C. E. Intelligentsia e intelectuais: sentidos, conceitos e possibilidades para a história intelectual. Revista Brasileira de História da Educação, Campinas, v. 8, n. 1, p. 63-85, jan./abr. 2008. Disponível em: <http://www.rbhe.sbhe.org.br/index.php/rbhe/ article/view/109>. Acesso em: 01 abr. 2015.

VIEIRA, C. E. Erasmo Pilotto: identidade, engajamento político e crenças dos intelectuais vinculados ao campo educacional no Brasil. In: ALVES, C.; LEITE, J. L. (Org.). Intelectuais e história da educação no Brasil: poder, cultura e políticas. 1. ed. Vitória: EDUFES, 2011.

VIEIRA, C. E. Contextualismo linguístico: contexto histórico, pressupostos teóricos e contribuições para a escrita da história da educação. Revista Brasileira de História da Educação, Maringá, v. 17, n. 3, p. 43-67, jul./set. 2017. Disponível em: <http://rbhe. sbhe.org.br/index.php/rbhe/article/view/922>.

VIEIRA, C. E.; BONA JR., A. Modernidade e educação nas conferências educacionais na década de 1920 no Paraná. In: VIEIRA, C. E. (Org.). Intelectuais, educação e modernidade no Paraná (1886-1964). Curitiba, UFPR, 2007. 


\section{Documentos consultados}

ASSOCIAÇÃO BRASILEIRA DE EDUCAÇÃO. Carta aberta aos sócios. A Pátria. 20 de fevereiro de 1933, s/p., Arquivo Carmem Jordão, Rio de Janeiro.

ASSOCIAÇÃO BRASILEIRA DE EDUCAÇÃO. Série: Atas de Sessões (1924-1967). Arquivo Carmem Jordão, Rio de Janeiro.

ASSOCIAÇÃO BRASILEIRA DE EDUCAÇÃO. Notícias da ABE (1927-1960). Arquivo Carmem Jordão, Rio de Janeiro.

ASSOCIAÇÃO BRASILEIRA DE EDUCAÇÃO. Estatuto da Associação Brasileira de Educação, Arquivo Carmem Jordão, Rio de Janeiro, 1924.

ASSOCIAÇÃO BRASILEIRA DE EDUCAÇÃO. Correspondências. Arquivo Carmem Jordão, Rio de Janeiro.

ASSOCIAÇÃO BRASILEIRA DE EDUCAÇÃO. Anais das CNEs (1927-1967). Arquivo Carmem Jordão, Rio de Janeiro.

ASSOCIAÇÃO BRASILEIRA DE EDUCAÇÃO. Teses (1927-1967). Arquivo Carmem Jordão, Rio de Janeiro.

ASSOCIAÇÃO BRASILEIRA DE EDUCAÇÃO. Esboço do Plano Nacional de Educação. In: Da Educação Nacional: sugestões da V conferência nacional de educação à Assembleia Constituinte. Janeiro de 1933, Arquivo Carmem Jordão, Rio de Janeiro 1933.

ASSOCIAÇÃO BRASILEIRA DE EDUCAÇÃO. Anais do VII Congresso Nacional de Educação. Arquivo Carmem Jordão, Rio de Janeiro, 1935.

ASSOCIAÇÃO BRASILEIRA DE EDUCAÇÃO. Anais do VIII Congresso Nacional de Educação. Arquivo Carmem Jordão, Rio de Janeiro, 1944.

MEMORIAL LYSÍMACO FERREIRA DA COSTA, Curitiba. I Conferência Nacional de Educação (teses), 1927.

Texto recebido em 03 de julho de 2017.

Texto aprovado 05 em julho de 2017. 